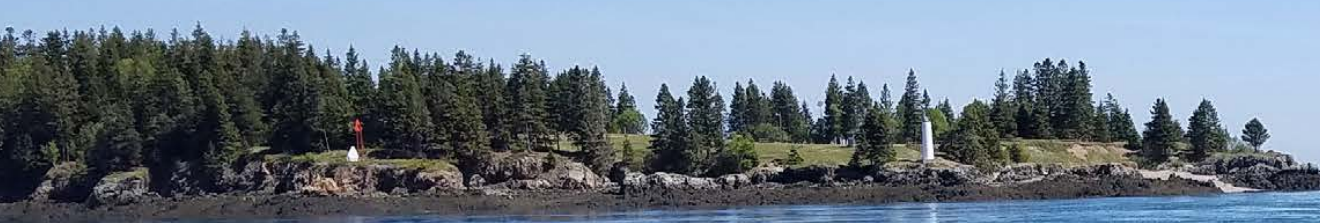

Whirlpool in Western Passage at the entrance to Passamaquoddy Bay, with

Deer Island in the background.

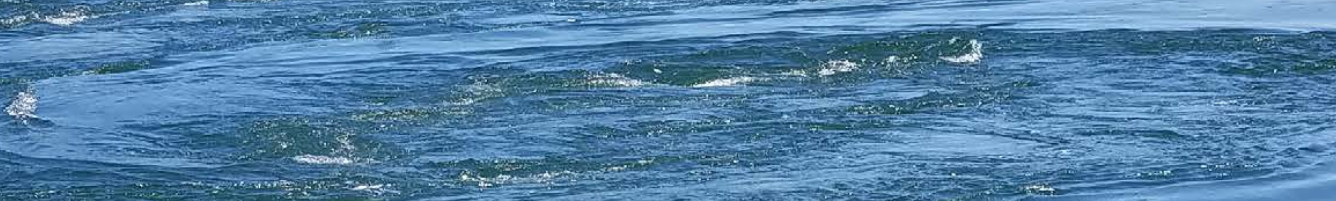

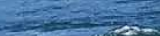

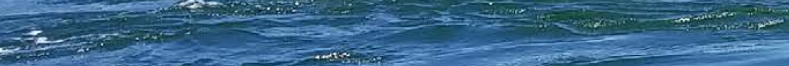
2

\title{
Interdisciplinary Research Collaborative Trains Students to See Through Turbulent Systems
}

By Kristina Cammen, Gabriella Marafino, Sarah Burton, Jillian Dow, Emma Dullaert, Madalyn Jorge, Kate Macolini, Louise McGarry, Christopher Tremblay, Jessica Jansujwicz, Tora Johnson, Lauren Ross, and Gayle Zydlewski
ABSTRACT. Despite the availability of interdisciplinary academic training programs, the practice of environmental science is often hampered by a lack of convergence across diverse disciplines. This gap is particularly salient in settings characterized by complex environmental issues, such as multiple-use coastal ecosystems. In response, we developed and implemented a training, research, and communication framework to provide undergraduates with an authentic operative experience working at the interface of interdisciplinary science and public decision-making within a case study of marine renewable energy. In our program, students gained hands-on experience with the scientific process and learned how to make information relevant, useful, and accessible to diverse stakeholder groups. Application of this framework demonstrates that the process of integrating data from biological (visual and acoustic monitoring of fish and marine mammals), physical (hydrodynamics), and social (local ecological knowledge) sciences can provide a more complete understanding of complex and turbulent ecosystems for better informed decisionmaking. We offer several recommendations to facilitate the adaptation and implementation of our interdisciplinary framework to diverse research contexts, with a focus on interdisciplinary training for the next generation of marine scientists. 


\section{INTRODUCTION}

Environmental science is inherently an interdisciplinary field, with academic training programs that include coursework in the physical, biological, and social sciences. Yet, the practice of environmental science is often hampered by a lack of convergence among these diverse disciplines. This gap exists despite significant efforts to design training programs in environmental and sustainability sciences that aim to prepare students to "craft usable knowledge" through interdisciplinary collaborations and stakeholder partnerships (S.G. Roy et al., 2019). Improvements to curriculumbased training programs alone may not be sufficient to produce environmental practitioners that are fluent in interdisciplinary research and communication. These limitations are particularly salient in settings that are characterized by complex and dynamic environmental and societal issues, such as coastal oceans.

Here, we describe the development and implementation of a training, research, and communication framework to provide undergraduates with an authentic experience working at the interface of interdisciplinary science and public decisionmaking within the context of marine renewable energy. Students are increasingly interested in professional paths that offer active engagement in solving sustainability problems. Recognition of the benefits of using a sustainability science problem, such as marine renewable energy, as a focal point for student training is emerging (Hart et al., 2016). By bringing together faculty and students from different disciplines to actively engage in solving a complex sustainability science problem, we aim to "re-envision the role of students" and build future capacity (Hart et al., 2016).

We established the Western Passage Student Research Collaborative (WPSRC) in the spring of 2019 to engage undergraduates in a one-year training program focused on research relevant to an area of growing interest and contention: the development of marine renewable energy in coastal areas and the associated need for environmental impact monitoring. Traditional environmental monitoring programs often fall short in settings where environmental impacts are likely to be highly complex and distributed across diverse components of an ecosystem (Thomas, 1993; Maurer et al., 1999). Effects of renewable energy development in coastal systems can include, for example, changes to the physical structure of an environment, altered biology, and cascading effects on associated natural resource-dependent human communities (Dadswell et al., 1986; CullenUnsworth et al., 2013; McDowell and Ford, 2014). Policy development and decision-making in these systems are further complicated by multiple, competing marine resource uses and uncertainty surrounding cumulative impacts (Lester et al., 2010; Fox et al., 2017).

Although several frameworks for holistic monitoring and management of coastal ecosystems have been proposed (Levin et al., 2009; Christie, 2011; Alexander et al., 2019), their implementation is stymied by barriers to integration across different disciplines and different types of knowledge (Cash, 2006). In particular, synthesizing knowledge into a form that is practical for managers to use in making day-to-day decisions continues to be a significant challenge (Clark et al., 2016). Efforts to strengthen research collaborations that transcend disciplinary approaches and include input from various communities of knowledge, including all relevant disciplines and stakeholder groups, has gained considerable momentum (e.g., Lang et al., 2012). However, while these previous experiences offer guidance on what should be considered when designing and conducting integrative collaborative research (e.g., Jansujwicz and Johnson, 2015), student training opportunities are not explicitly considered. A lack of such opportunities to provide upcoming marine scientists with practice in interdisciplinary thinking outside of the more traditionally disciplinary-distinct class- room setting hampers efforts to translate knowledge into action.

In this paper, we first outline our training, research, and communication framework and describe the case study that motivated the development of the WPSRC. We then share how undergraduates were engaged in an integrated approach to data collection, analysis, and communication, and discuss the challenges we faced along the way. We conclude by offering several recommendations to facilitate the adaptation and implementation of our interdisciplinary, student-focused framework to diverse research contexts.

\section{AN INTERDISCIPLINARY TRAINING, RESEARCH, AND COMMUNICATION FRAMEWORK}

The University of Maine is one of many institutions nationwide that promote interdisciplinary research to train undergraduates in innovative and integrative ways of thinking (Davis et al., 2015; S.G. Roy et al., 2019). Multidisciplinary and team-based approaches to undergraduate research have been shown to promote students' academic engagement (Koch et al., 2017) and their acquisition of skills important for employability following graduation (Juhl et al., 1997; Doerschuk et al., 2016). We approached these goals through a training, research, and communication framework that engaged students, alongside research mentors and diverse stakeholders (e.g., industry and community members, policy- and decision-makers), with the integration of physical, biological, and social science data relevant to a current environmental and societal issue (Figure 1). The key tenets of our framework include (1) a training program that emphasizes experiential, bidirectional learning across diverse epistemologies, (2) an interdisciplinary research program that is intentionally open to iteratively reconsidering objectives and methodologies to ensure their continued relevance, and (3) a communication plan that emphasizes reflexive communication among researchers and stakeholders. 
TRAINING. The research collaborative intentionally included people from different disciplines (e.g., physical, biological, and social sciences), different career stages (e.g., undergraduate to early career and tenured faculty), and different career tracks (e.g., academic and non-academic), who each brought their own way of knowing or seeing the world (i.e., unique epistemologies). The WPSRC included five undergraduates who were co-mentored by individuals from different disciplines, including one graduate student, five faculty, two research associates, and one marine extension associate. WPSRC members represented the diverse fields of marine biology, coastal engineering, human dimensions of natural resources, and geospatial sciences. Explicitly acknowledging the value of this diversity encouraged bidirectional learning, with students learning from faculty and vice versa. As part of our one-year interdisciplinary research collaborative, students gained hands-on experience that puts the training they receive in the class- room into practice. Students engaged with the scientific process from start to finish, including planning and executing fieldwork and data analyses as well as presenting research findings in written and oral formats. Through turning data into stories and stories into data, students gained insight into how to make information relevant, useful, and accessible.

RESEARCH. Drawing upon discrete disciplinary areas of expertise, our initial approaches to the research were based within the methods and practices of singular disciplines. However, the process of troubleshooting challenges in data collection and interpretation required that we remain open to revisiting objectives and methodological approaches, and to bringing in new disciplinary experts as questions arose that required additional insights. In fact, the WPSRC was itself an outcome of such an iterative process, being identified as a need when traditional monitoring approaches fell short, as described further below.
COMMUNICATION. Our stakeholderengaged approach to data collection and sharing emphasizes the need for proactive and transparent communication throughout the interdisciplinary research process. We committed to frequent meetings in person or via remote conferencing to provide space and time for formal and informal discussions and learning. Interdisciplinary discussions at full research collaborative meetings were fodder for "aha" moments that are harder to come by in isolation. Communication with stakeholders was key to ensuring research questions were informed by stakeholder needs and research products were presented in a usable and useful form that encouraged the uptake of information.

As a result of the persistent and engaged commitment of all team members to the tenets of our training, research, and communication framework, the WPSRC successfully integrated diverse data sources to contribute to a more complete under-

\section{Contemporary environmental and societal issue: Marine renewable energy}

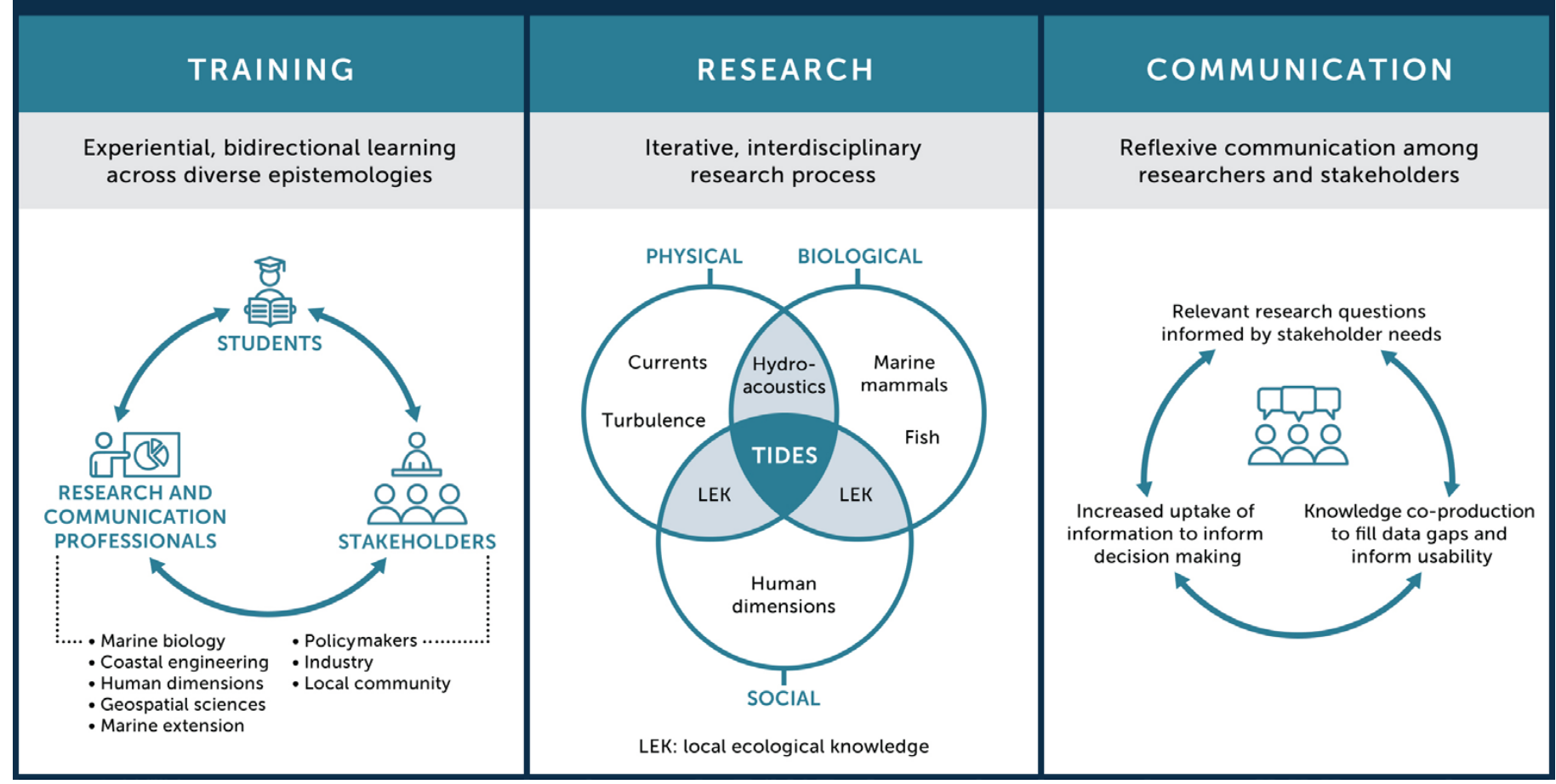

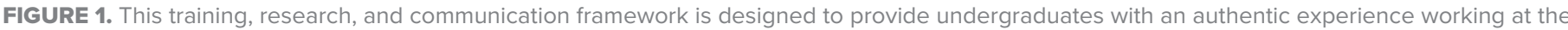
interface of interdisciplinary science and public decision-making within the context of marine renewable energy. 
standing of a complex, turbulent coastal ecosystem. By adopting a stakeholderengaged approach, we ensured that our research questions and outputs are relevant, useful, and accessible to better support informed decision-making around coastal development, using marine renewable development as an exemplary case. Students participating in this interdisciplinary work built a transferable skill set that will be broadly applicable and desirable as they progress along their chosen career paths.

\section{A CASE STUDY OF MARINE RENEWABLE ENERGY}

Western Passage is located between Maine and New Brunswick, Canada, near the gateway to one of North America's preeminent tidal energy (hydrokinetic) resources in the Bay of Fundy (Figure 2). This region has been the focus of proposed renewable energy since the 1940s, with renewed interest over the past decade. Western Passage ranks as one of the top five most promising hydrokinetic energy sites in the United States (Kilcher et al., 2016), but it is also a unique and valuable natural environment. It includes iconic physical (largest tidal whirlpool in the Western Hemisphere), biological (habitat for endangered marine mammals), and social (traditional and commercial fishing grounds, ecotourism attractions) features that require careful consideration in coastal development. The combination of these factors creates a broadly defined "turbulent system," with both physical and social contributions to turbulence.

The confluence of tides combined with complicated seafloor topography creates a complex hydrodynamic environment dominated by strong current velocities and physical turbulence, as well as iconic eddies and whirlpools (Figure 2). Water moving through Western Passage, which ranges from $1.3 \mathrm{~km}$ to $2.8 \mathrm{~km}$ wide and approximately $30 \mathrm{~m}$ to $120 \mathrm{~m}$ deep at mid-channel (https://maps.ngdc.noaa.gov/ viewers/bathymetry/), can reach velocities of approximately $3 \mathrm{~m} \mathrm{~s}^{-1}$ at peak tidal current flow (Rao et al., 2016).

Social turbulence in this system results from past and ongoing changes to the socio-ecological system of Western Passage and its surrounding communities. For centuries, fish and other marine resources in this region have held significant spiritual, cultural, and subsistence value for indigenous Passamaquoddy communities (Bassett, 2015). The herring fishery was also central to the economic vitality of this region until its decline, and the loss of associated fish processing plants (canning, drying, and smoking) during the mid to late 1900 s resulted in increased unemployment, poverty, and outmigration (Johnson et al., 2014). More recently, this area has witnessed additional natural resource declines and subsequent regulations that have limited access to key fisheries, such as groundfish, urchin, and scallops (Hall-Arber et al., 2001). To address social turbulence and remain viable and resilient, these communities rely on alternative economic opportunities outside of fishing, such as
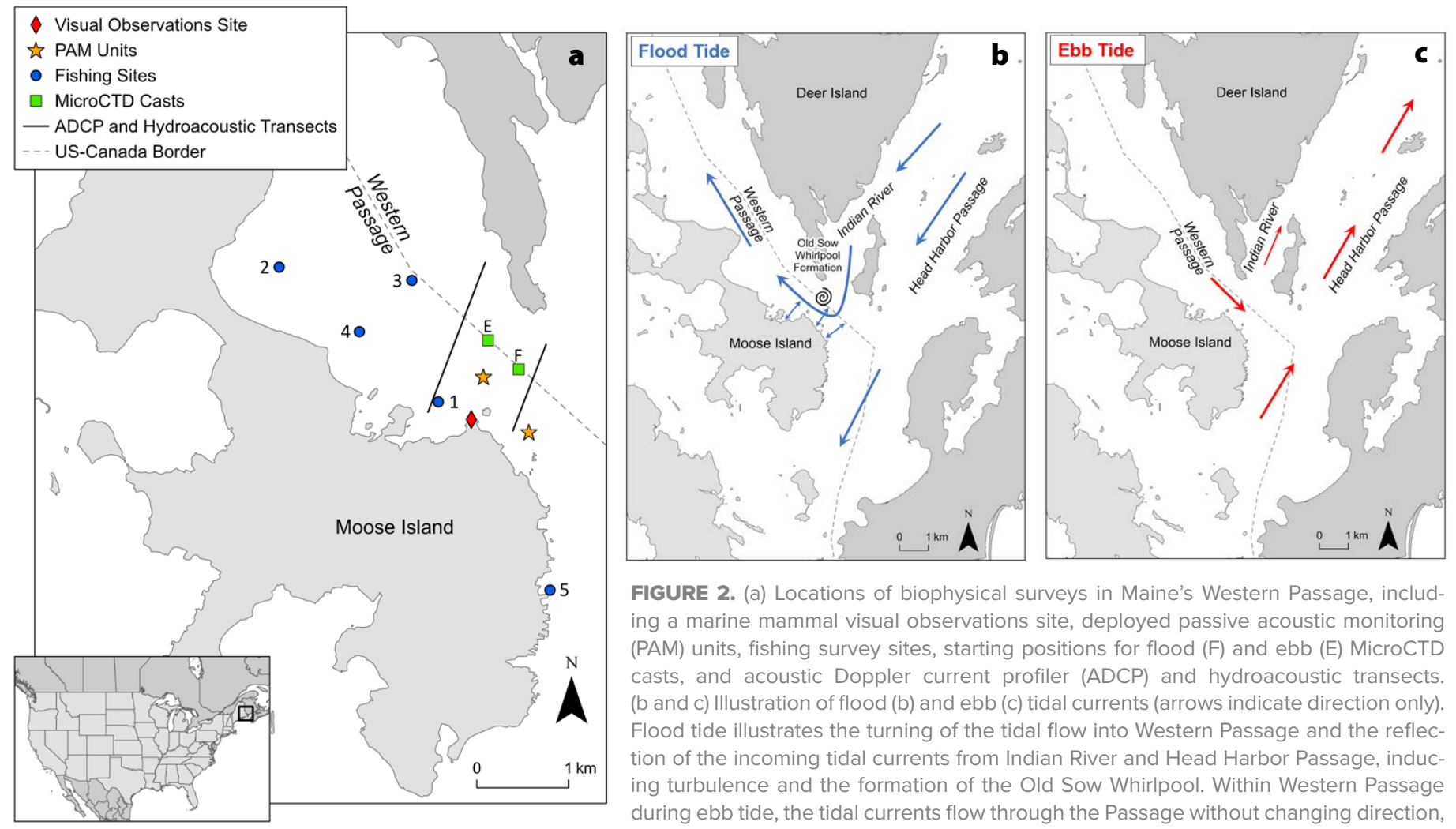

FIGURE 2. (a) Locations of biophysical surveys in Maine's Western Passage, including a marine mammal visual observations site, deployed passive acoustic monitoring (PAM) units, fishing survey sites, starting positions for flood (F) and ebb (E) MicroCTD casts, and acoustic Doppler current profiler (ADCP) and hydroacoustic transects. (b and c) Illustration of flood (b) and ebb (c) tidal currents (arrows indicate direction only). Flood tide illustrates the turning of the tidal flow into Western Passage and the reflection of the incoming tidal currents from Indian River and Head Harbor Passage, inducing turbulence and the formation of the Old Sow Whirlpool. Within Western Passage during ebb tide, the tidal currents flow through the Passage without changing direction, and elevated turbulence and whirlpools do not result. This figure was adapted from Figure 4 presented in International Passamaquoddy Fisheries Board (1960). 
marine tourism and renewable energy development (Johnson et al., 2014).

Environmental monitoring and decision-making around tidal energy development is complicated by the physical and social turbulence that typifies
In addition, a focus on student training can attract new sources of funding for such efforts. The WPSRC emerged as a strategy for overcoming barriers to interdisciplinary science and problem solving by placing student training at the fore-
Importantly, these studies have infrequently considered ecosystems as a whole and have often excluded the human component (Bonar et al., 2015).

Ironically, the impressive currents that are favorable to tidal energy develop-

\section{The professional relationships that developed between students, research}

mentors, and diverse stakeholder groups during this year of study and the experiential learning gains achieved across all levels provide critical building blocks for further exploration of this system and others.

coastal ecosystems like Western Passage. Yet, with the growing interest in developing marine energy technologies and other coastal infrastructure, managers are increasingly called upon to make timely decisions regarding the siting and permitting of new marine uses despite significant data gaps. Over the past 10-15 years, tidal energy development and commercialization have been significantly hampered by lack of data or data that are insufficient or not well integrated into a form that can be readily used (Leeney et al., 2014; Copping, 2018).

Key challenges that contribute to these critical data gaps were identified by the Maine Tidal Power Initiative (MTPI) during an earlier effort to bring together stakeholders and researchers from different disciplines to address questions related to tidal power development. Securing funding for large interdisciplinary initiatives $(\sim \$ 1.5 \mathrm{M}$ annually, in this case) and the high level of commitment required to sustain and manage them were two of the challenges identified. The MTPI also found that student involvement can foster linkages between disciplinary teams and is critical to training the next generation of scientists and decisionmakers (Jansujwicz and Johnson 2015). front of developing, implementing, and evaluating an ecosystem-level monitoring program. Our research collaborative was funded through an internal institutional grant for interdisciplinary student training programs.

\section{INTEGRATING DIVERSE DATA SOURCES ILLUMINATES THE IMPORTANCE OF TIDES}

Demonstration and testing of new marine renewable energy technologies have thus far resulted in mostly singular disciplinary knowledge of the potential effects of tidal power on marine animals and hydrodynamics. For example, in our previous research, we discovered that fish were commonly present in the wake of a test turbine, that schools of fish had a lower probability of entering a turbine than individual fish (Viehman and Zydlewski, 2015), and that fish counts were not linked to current speed (Viehman and Zydlewski, 2017). Studies of how tidal turbine farms impact hydrodynamics elsewhere have found that tidal turbines may locally reduce current velocities in estuaries and tidal channels, which can ultimately lead to a decrease in sediment fluxes (Defne et al., 2011; Fallon et al., 2014; Thiébot et al., 2015). ment, such as those in Western Passage, pose one of the challenges to conducting ecosystem-level studies (i.e., studies that integrate across these traditionally siloed disciplines) (Melvin and Cochrane, 2015). Many research approaches that are typically used to monitor marine species (e.g., hydroacoustics, trawling, passive acoustic monitoring) have limited capability for collecting viable data throughout such dramatic tidal cycles. To overcome this challenge, the WPSRC drew upon the expertise, tools, and theories of diverse natural and social science disciplines to study the fish, marine mammals, humans, and hydrodynamics of Western Passage (Figure 3). Our aim was to engage students and stakeholders in the design and implementation of an interdisciplinary research program that would lead to a better understanding of baselines across multiple components of this complex ecosystem.

Overall, our integrated approach to data collection and analysis revealed a common theme across all data types. Tidal dynamics were found to be a significant factor affecting biological, physical, and social data, highlighting their importance to the Western Passage ecosystem and future monitoring programs 


\section{Project Timeline \& Objectives}

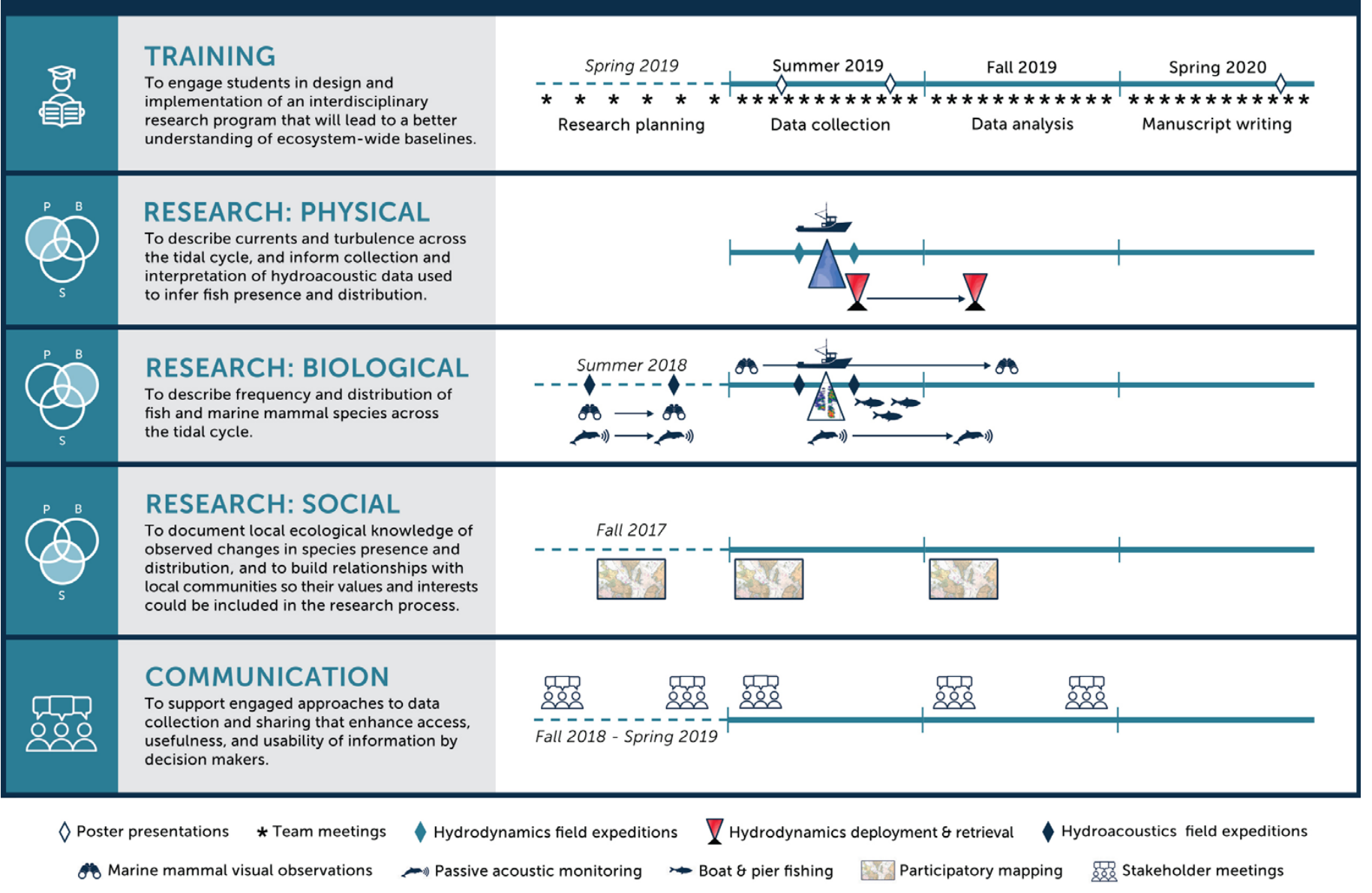

FIGURE 3. Timeline and objectives for training, research, and communication elements that undergraduates participated in as part of the Western Passage Student Research Collaborative (WPSRC) from May 2019 to May 2020. Research included disciplinary and interdisciplinary physical (P), biological (B), and social (S) science components. Preceding activities (dashed lines in the timelines) that informed WPSRC activities were conducted by research mentors and a graduate student research assistant.

for coastal development in this region. Recognizing this link enabled synergies between data streams that would not have been possible if each were considered alone. Here, we provide an overview of the research methods employed by our student research collaborative and the preliminary findings that were an outcome of our focus on integrating disciplines to better understand a tidally dynamic ecosystem. Further details on individual methods are provided in the online supplementary materials.

\section{Hydrodynamics Inform Biological Data Collection}

A primary goal of our research collaborative was to describe the currents and turbulence of Western Passage across the tidal cycle in ways that would inform biological data collection. This goal was intentionally envisioned to integrate physical and biological components of our research team. Hydroacoustic methods, using sonar, are employed to increase understanding of many components of aquatic ecosystems, including bathymetry and the presence and distribution of fish (Shen et al., 2016; Viehman et al., 2018; Staines et al., 2019). However, it is difficult to collect data using hydroacoustic methods in highly turbulent environments because the presence of velocity shears and air entrained in the water can obfuscate the backscatter from biological sources (Ross and Lueck, 2005; Lavery et al., 2007; Warren and Wiebe, 2008). To quantify the influence of physical forces on biological data collection, biologists and coastal engineers collaborated to concurrently collect hydroacoustic and hydrodynamic data (turbulence and current velocities). Throughout a spring and a neap tidal cycle in Western Passage, WPSRC students gained hands-on technical training while working alongside their research mentors during fieldwork and subsequent analysis of data collected in Western Passage.

Integration of the concurrently collected hydrodynamic and hydroacoustic data was critical to documenting the source (physical or biological) of the dominant backscatter signal observed in Western Passage throughout each tidal cycle. The concurrently collected hydroacoustic, turbulence, and current veloc- 
ity data sets together showed that elevated backscatter observed during the flood tide co-occurred with the period of strongest mixing rates (Figure 4). Together, these data suggest that the high level of backscatter measured during the dynamic flood-tide flow in Western Passage was not solely from a biological source (i.e., fish) and precluded our ability to use hydroacoustics to observe the distribution and abundance of fish. These findings confirm that traditional hydroacoustic approaches have limited capacity in this physically turbulent system, necessitating alternative monitoring approaches to observe biological activity during the flood tide.

\section{Observing Across Trophic}

Levels Indicates the Importance of the Flood Tide

With guidance from biological oceanographers who provided knowledge of tidal influence on species biology, marine ecologists who considered the trophic relationships among species, and social scientists who focused on the human dimensions and value of local ecological knowledge, the WPSRC developed alternative monitoring approaches to describe the frequency and distribution of fish and marine mammal species in Western Passage. This component of our research was in part motivated and guided by decision-makers, including federal and state regulators who incorporate baseline information on marine species when considering permitting of marine renewable energy projects. To fulfill these needs, the WPSRC sought to describe the frequency and distribution of species across trophic levels, including fish and the marine mammals that feed on fish.

Given that the fast-flowing and highly turbulent conditions preclude safe and effective net tows to ground truth hydroacoustic data, regulators who were engaged in decision-making around marine permitting in this region recom-

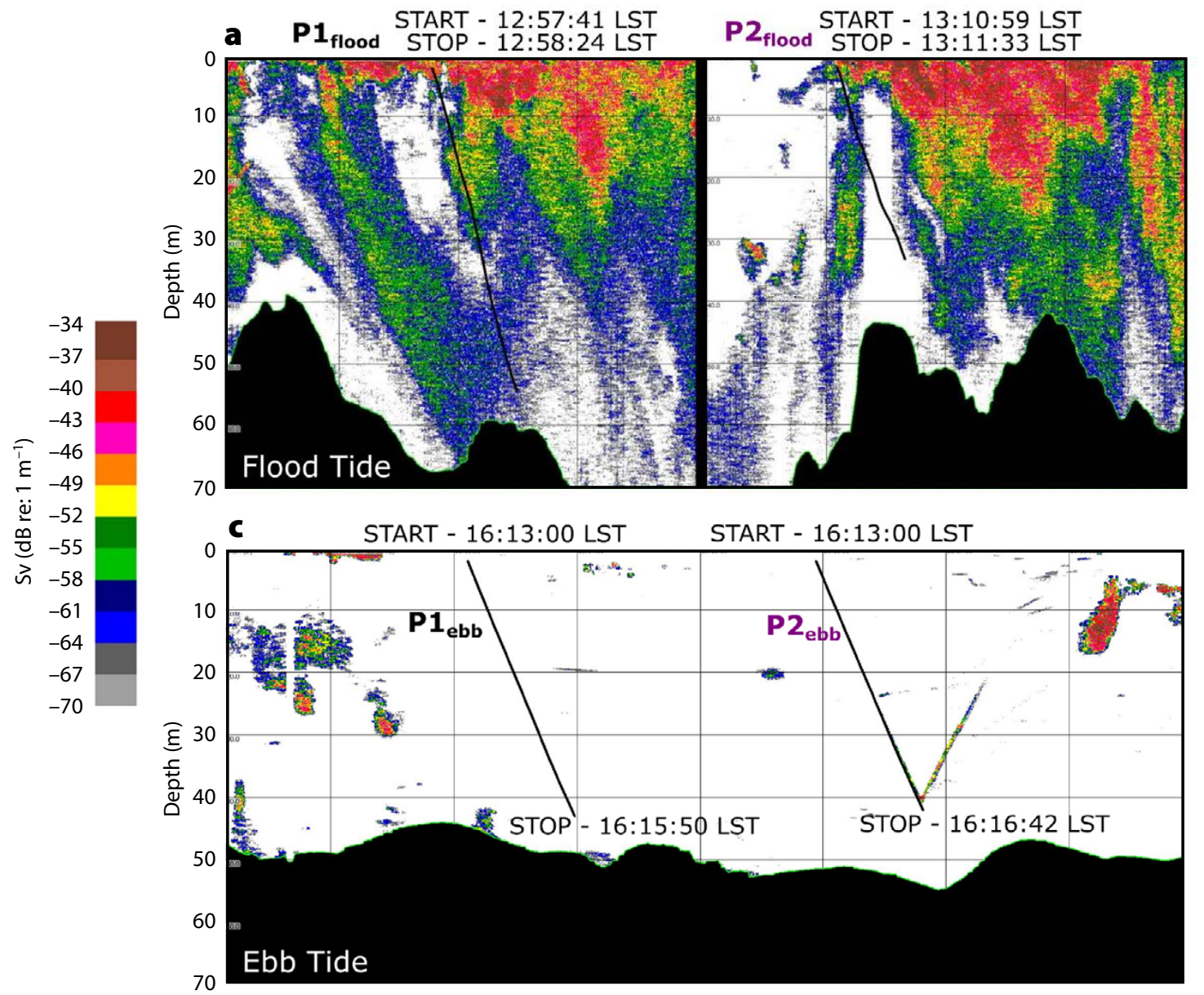

b

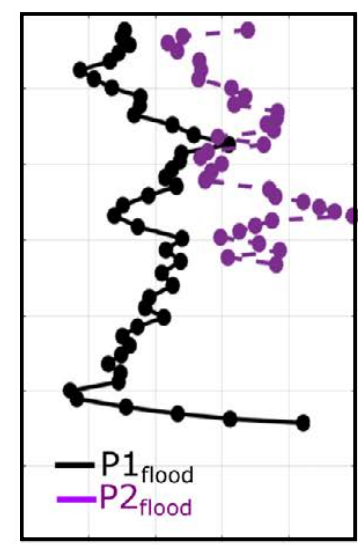

d

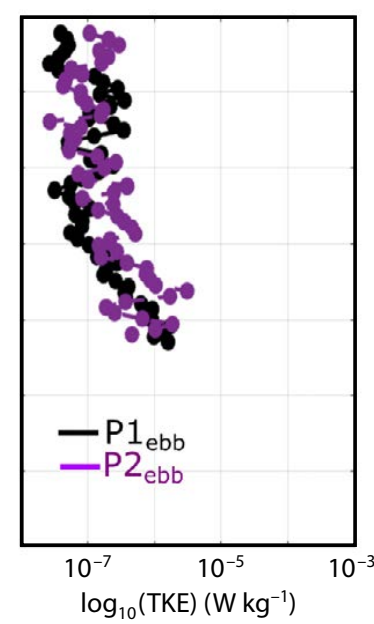

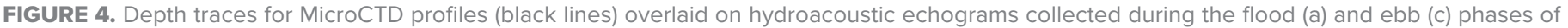

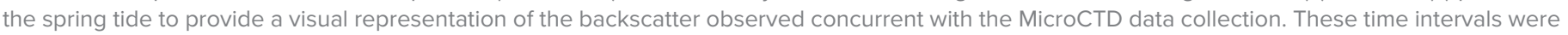

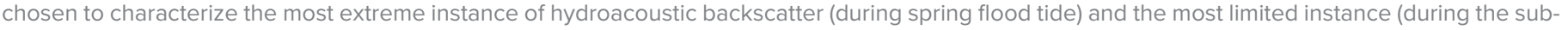

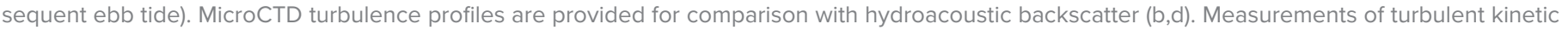

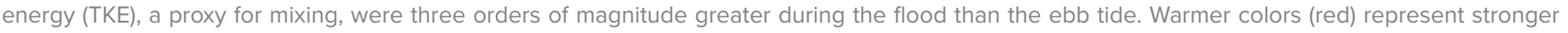

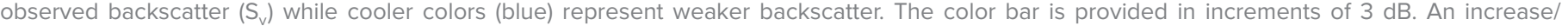

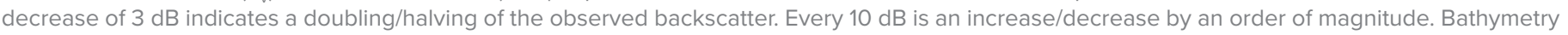
is indicated by the black region at the bottom of the echograms. 
mended testing recreational fishing gear as an alternative approach. WPSRC students worked with a marine extension associate to test fishing with sabiki rigs, which are equipped with several small hooks, as a method to characterize species presence and size. In July and August 2019, four boat-based sites and one landbased site were surveyed. Our diverse catch of both pelagic and ground fish suggests that fishing with recreational gear can provide insights into fish biodiversity in the region.

From May to October 2019, WPSRC students, research associates, and faculty with marine mammal expertise also used a combination of visual surveys and passive acoustic monitoring to study marine mammals in Western Passage. Through the iterative process of collaboratively creating and testing survey protocols, students learned firsthand about the logistics and challenges associated with both landand boat-based marine mammal research in a tidally dynamic system. The marine mammal species we most commonly sighted in Western Passage was the harbor porpoise (Phocoena phocoena). The students observed these small odontocetes during almost every one of their twice weekly visual surveys, detecting them during all hours of acoustic recordings from July through October. The harbor porpoise were most frequently seen and heard during the flood tide, with detections increasing as water levels increased in Western Passage and declining as water levels ebbed (Figure 5).

Students integrated data from fishing and marine mammal surveys to test hypotheses that may explain trends in biological activity in Western Passage; for example, does the increase in harbor porpoise detections during the flood tide correlate with increased prey/fish abundance in the Passage? Atlantic mackerel (Scomber scombrus), the fish most frequently caught in Western Passage with recreational fishing gear, is a common prey species for harbor porpoise (Smith and Gaskin, 1974). Our preliminary analyses suggest a significant pos- itive relationship between water level and harbor porpoise detections but not mackerel catch during the flood tide (Figure 5), yet importantly, our fishing efforts did not cover the full tidal range or target all prey species. We therefore present these preliminary results primarily as an example of the ecological hypotheses that students explored using a data integration approach.

\section{Expanding Understanding in}

Time and Space Through Local

\section{Ecological Knowledge}

The WPSRC's final research objective was to document local ecological knowledge in the Western Passage region in order to expand the temporal and spatial resolution of the knowledge gained through biophysical surveys. Although participatory methods and alternative sources
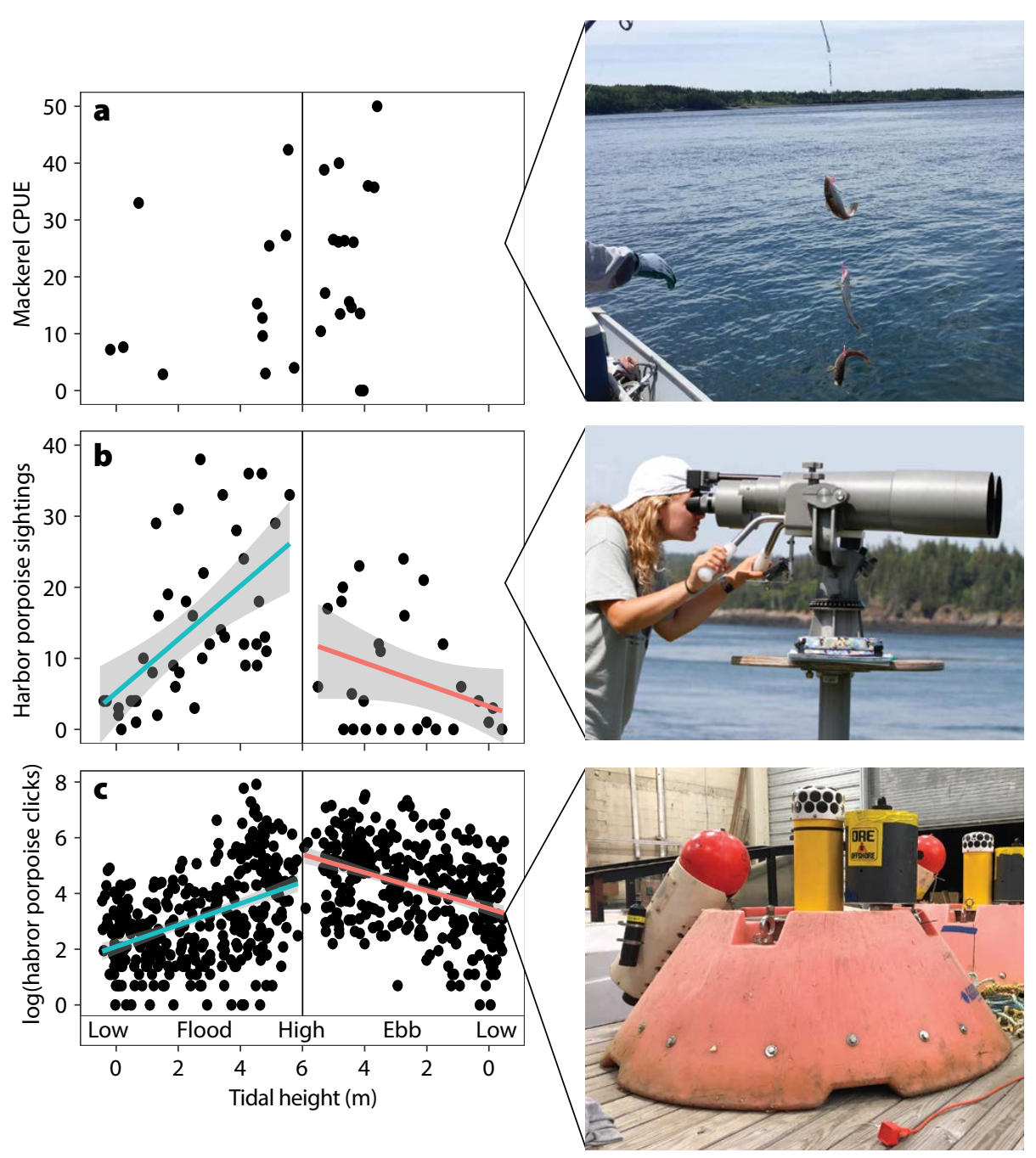

FIGURE 5. Integration of discrete data sets from fishing, marine mammal visual surveys, and passive acoustic monitoring to assess relationships between detections of prey and predators across the tidal cycle during a one-month period (September 9, 2019-August 8, 2019) in Western Passage. Fish and porpoise detections are compared to verified tidal heights extracted from NOAA Tide \& Currents database (https://tidesandcurrents.noaa.gov/) for the Eastport, Maine, station. (a) Catch per unit effort (CPUE by hour) of mackerel caught using recreational fishing gear at four boat-based sites in Western Passage (blue circles, Figure 2). (b) Number of harbor porpoise sighted per halfhour of visual land-based survey from Eastport (red diamond, Figure 2). (c) Harbor porpoise clicks detected per half-hour from a passive acoustic recorder deployed in Western Passage (western yellow star, Figure 2). Significant linear models predicting detections from water level, with shaded 95\% confidence interval, are shown for harbor porpoise sightings on flood $\left(F_{1,40}=19.61, p<0.0001\right.$, $\left.r^{2}=0.329\right)$ and ebb tides $\left(F_{1,28}=4.705, p<0.05, r^{2}=0.144\right)$, and for harbor porpoise clicks on flood $\left(F_{1,357}=30.83, p<1 \times 10^{-7}, r^{2}=0.079\right)$ and ebb tides $\left(F_{1,378}=34.91, p<1 \times 10^{8}, r^{2}=0.085\right)$. Relationships between mackerel CPUE and tidal height were not significant during either tide. 
of knowledge are increasingly appreciated for their contributions to designing more effective monitoring protocols (Chambers, 2006), acknowledgment of local communities as an important source of place-based knowledge is often missing when researchers attempt to understand an ecosystem (Mackinson and Nottestad, 1998; Ames, 2003; Teixeira et al., 2013). The WPSRC therefore used an engaged and participatory approach, as described below and in the online supplementary materials, to gather and share data with local communities. A strong baseline of trust that emerged from earlier MTPI interactions between the research team and individual community members contributed significantly to critical longterm working relationships (Jansujwicz and Johnson, 2015).

Beyond its value for biological data collection, a secondary objective for fishing with recreational gear from one landbased site (a local pier) was for students to engage with local fishermen, note their observations of fish in the area, and gain an understanding of how fish and fishing are valued within the community. In addition to informal conversations at the pier, the WPSRC also convened a public meeting to engage community members, including local commercial and recreational fishermen, in participatory mapping exercises. This meeting built off an earlier public meeting in the local community where community members shared personal connections to the adjacent Western Passage and recorded their knowledge of fish and other marine species directly on hard-copy nautical charts (Figure 6). This recorded knowledge included memories of observed changes in the ecosystem over time, as well as how species presence fluctuates daily with the tidal cycle.

Integration of local ecological knowledge regarding fish and marine mammal presence significantly expanded the temporal and geographic scope of our understanding of the ecological community beyond our hydroacoustic transect lines and the limited scope of our fishing and marine mammal observation sites. Furthermore, engaging with the local community also led to other collaborative efforts, including working with fishermen to collect fishing and phenology data that will further expand our understanding of the Western Passage ecosystem. We aim for these additional data to ultimately be incorporated into decision support tools, such as those described in the following section, alongside the data collected by the WPSRC students.

\section{Data Visualization Strengthens Decision-Support Tools}

Data visualization in space became a key WPSRC tool for integrating, interpreting, and communicating different kinds of knowledge. Maps constructed through participatory mapping activities formed the foundation for a geospatially referenced collection of local ecological knowledge. Adding our contemporary fish capture and marine mammal sighting data to these maps of recent and historical observations contributed to our understanding
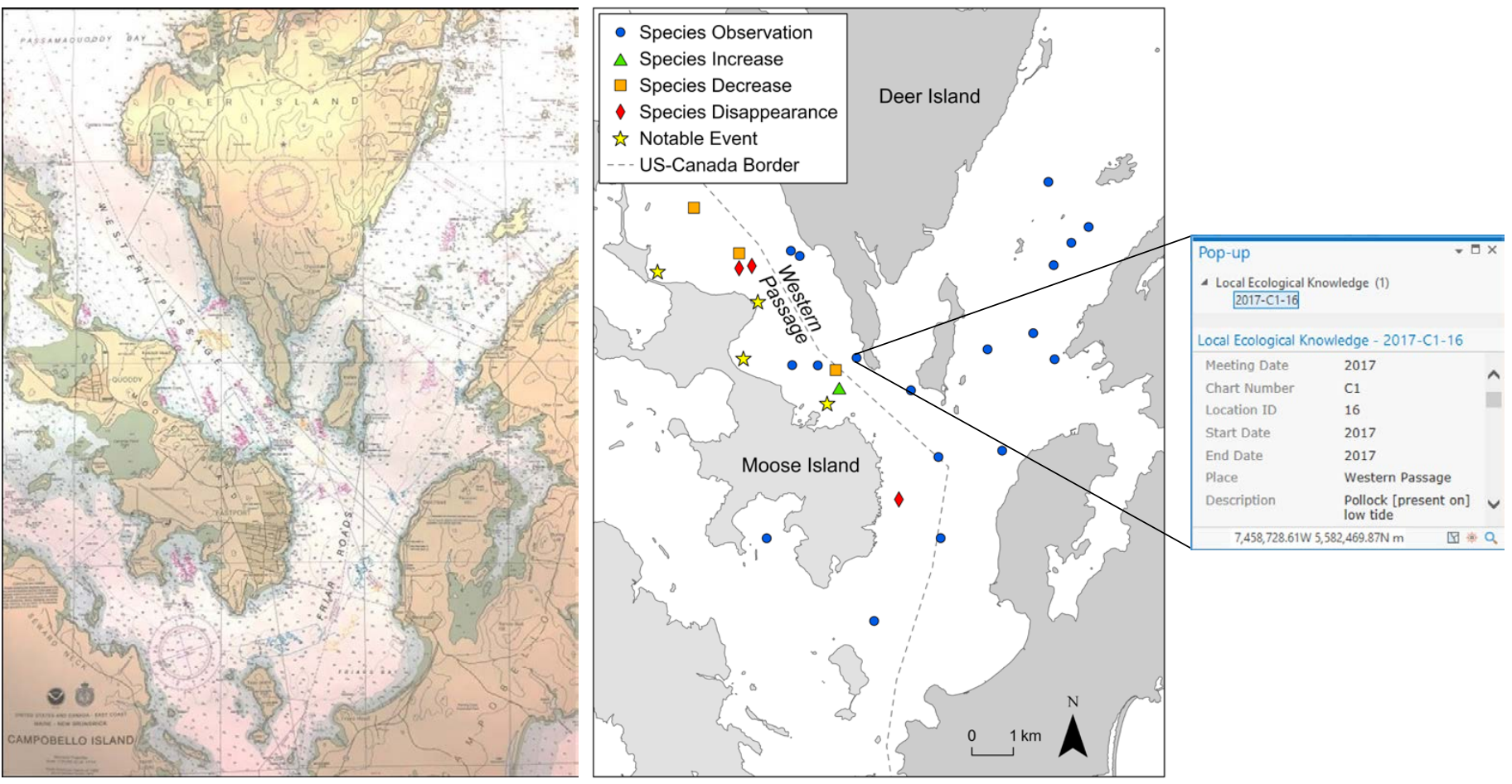

FIGURE 6. Nautical chart used in the participatory mapping activity (left panel) with handwritten local ecological knowledge collected during a 2017 community meeting in Eastport. We intentionally did not zoom in to these handwritten notes for confidentiality purposes. These data were digitized using ArcGIS Pro to produce an interactive map (middle panel). A "notable event" on these maps is defined as an unusual or noteworthy occurrence, such as legislation, development, or other human impact. Clicking on a selected point opens a pop-up window with the attribute table (right panel). 
of baselines and potential for change in species presence and distribution. Finally, a WPSRC student mentored by a geospatial scientist also worked to create a three-dimensional base map of bathymetry in Western Passage that provided critical context for interpreting how physical features affect biological and social dynamics in this turbulent environment.

Overlaying the student-collected data on this three-dimensional bathymetric model will ultimately form the basis of a web-based, interactive map that will be accessible to local community stakeholders and managers to inform future decision-making. We are continuing to add information from multiple sources to this map with feedback from stakeholders about its utility and their data needs. We view tools and maps like this one as components critical to an engaged, interdisciplinary, ecosystem-based monitoring approach. It represents a clear shift from the unidirectional information exchange that typifies traditional reporting of environmental monitoring data to a two-way exchange that determines how compiling all sources of information can be useful to communities (Cvitanovic et al., 2015).

\section{CHALLENGES AND RECOMMENDATIONS FOR EFFECTIVE INTERDISCIPLINARY TRAINING, RESEARCH, AND COMMUNICATION}

The experience of the WPSRC provides a striking example of what can be gained through the integration of diverse disciplines. However, this approach is not without challenges. Similar to other studies of interdisciplinary science, the primary challenges encountered by the WPSRC included the time commitment needed to coordinate with large and diverse research teams (E.D. Roy et al., 2013; Pischke et al., 2017) and the cognitive load required to engage meaningfully in conversations about unfamiliar disciplines and different ways of knowing (MacLeod, 2018). To address these challenges, members of our research collaborative shared coordination roles, with different individuals responsible for coordinating research team meetings and the overall student training experience, fieldwork, and communication with stakeholders. Faculty and students alike acknowledged and reflected upon the challenge and value of conducting interdisciplinary work regularly throughout the process. As evident in this article, maps often served as boundary objects for the WPSRC to foster dialogue and learning among this interdisciplinary and diverse group of collaborators (Cutts et al., 2011; Luna-Reyes et al., 2018).

To conclude, we reflect on the value of our training, research, and communication framework (Figure 1) and offer three general recommendations for facilitating the broader implementation or adaptation of the framework to other contexts in oceanography, marine ecology, coastal development, as well as nonaquatic environments.

\section{RECOMMENDATION 1: TRAINING}

Build a team that acknowledges the value of diverse epistemologies and bidirectional learning in student training. Our interdisciplinary framework was based on the equal involvement of people from different disciplines and different career stages who each brought their own way of knowing or seeing the world. As a training model, it was valuable for students to share the learning experience with their mentors, who were also learning from new disciplines. When forming our team, we considered the existing knowledge gaps in our study system and identified individuals with discrete areas of expertise who would approach data collection to fill these gaps in multiple, complementary ways. Students were co-mentored by practitioners from different disciplines. The inclusion of individuals with training and prior experience in collaborative research methods and undergraduate research mentoring, as well as the relatively small size of our collaborative, also contributed to our success. We acknowledge here the tradeoffs inherent in offering an in-depth training opportunity to a small number of students but suggest that some elements of our program provide a scalable structure. These elements include comentoring, clear roles and responsibilities, frequent meetings, and an emphasis on boundary objects as well as dedicated time and space to learn from different disciplinary perspectives.

\section{RECOMMENDATION 2: RESEARCH}

$\mathrm{Be}$ open to an iterative research process. A process with multiple aims and multiple disciplines is inherently complex, and this complexity often precludes defining a straight path to success at the beginning of the process. Rather, remaining open to an iterative process of revisiting objectives and methodological approaches was integral to our framework and allowed our research collaborative to be flexible and responsive to shifting needs. After recruiting students to our team, our first several meetings were focused on revisiting and refining research objectives and methodologies. Students presented their research proposal to an external audience of regional stakeholders at a local scientific meeting early in the project period. Following subsequent field trials, methods were further refined and new synergies among disciplines were discovered through this process.

\section{RECOMMENDATION 3: \\ COMMUNICATION}

Adopt a reflexive approach to communication within the research team and with external stakeholders. In all of our interactions, we remained open to adapting our approaches to how we conduct research to ensure that the questions we investigated fit the needs, values, and interests of diverse groups. Key to our ability to remain reflexive was a commitment to frequent meetings and both electronic and in-person communication. Students met weekly, or more frequently as needed, with their mentors. Our team held biweekly meetings of the full research collaborative (all students and their mentors) and approximately quar- 
terly meetings with diverse stakeholders (community members, managers, and industry). Students also had multiple opportunities to practice scientific communication through their participation in the writing and revising of this manuscript, as well as presentations at regional meetings with scientific, stakeholder, and general public audiences.

As a result of the persistent and engaged commitment of all team members to the principles listed above, the WPSRC successfully achieved outcomes in student training, research, and communication. We acknowledge that data from a single year of research limits our ability to accurately infer ecological interactions (Rehme et al., 2011) or estimate cumulative impacts of multiple anthropogenic activities (Lester et al., 2010; Fox et al., 2017) because neither was directly measured. Yet, through the collection and integration of diverse data sources, the WPSRC contributed to the creation of baseline knowledge of a complex, turbulent coastal ecosystem. The professional relationships that developed between students, research mentors, and diverse stakeholder groups during this year of study and the experiential learning gains achieved across all levels provide critical building blocks for further exploration of this system and others. Students gained transferable skills in disciplinary methods, interdisciplinary research approaches, and stakeholder engagement. These skills will set them up for success in a future sustainability science seascape that necessitates a convergence research approach. Finally, by embracing the commitment to sharing these data in highly visible forms that are available and accessible to stakeholders, the WPSRC contributed to future decision-making around coastal development in a physically, biologically, and socially valuable natural environment. Renewable energy development is still being considered in Western Passage, and a subset of team members remain engaged in research to support the decision-making process. @
SUPPLEMENTARY MATERIALS

The supplementary materials are available online at https://doi.org/10.5670/oceanog.2021.102.

\section{REFERENCES}

Alexander, K.A., A.J. Hobday, C. Cvitanovic, E. Ogier, K.L. Nash, R.S. Cottrell, A. Fleming, M. Fudge, E.A. Fulton, S. Frusher, and others. 2019. Progress in integrating natural and social science in marine ecosystem-based management research. Marine \& Freshwater Research 70:71-83, https://doi.org/ 10.1071/MF17248.

Ames, T. 2003. Putting fishermen's knowledge to work: The promise and the pitfalls. Pp. 184-188 in Putting Fisher's Knowledge to Work Conference Proceedings, August 27-30, 2001, Volume 11. Fisheries Centre Research Reports, Vancouver, Canada.

Bassett, E. 2015. Cultural Importance of River Herring to the Passamaquoddy People. Sipayik Environmental Department, Passamaquoddy Tribe, Pleasant Point Reservation, West Isles, ME, 25 pp.

Bonar, P.A.J., I.G. Bryden, and A.G.I. Borthwick. 2015 Social and ecological impacts of marine energy development. Renewable and Sustainable Energy Reviews 47:486-495, https://doi.org/10.1016 j.rser.2015.03.068.

Cash, D.W. 2006. Countering the loading-dock approach to linking science and decision making: Comparative analysis of El Nino/Southern Oscillation (ENSO) forecasting systems. Science, Technology \& Human Values 31:465-494, https://doi.org/10.1177/0162243906287547.

Chambers, R. 2006. Participatory mapping and geographic information systems: Whose map? Who is empowered and who disempowered? Who gains and who loses? The Electronic Journal of Information Systems in Developing Countries 25:1-11, https://doi.org/10.1002/j.1681 4835.2006.tb00163.x

Christie, P. 2011. Creating space for interdisciplinary marine and coastal research: Five dilemmas and suggested resolutions. Environmental Conservation 38:172-186, https://doi.org/10.1017/ S0376892911000129.

Clark, W.C., L. van Kerkhoff, L. Lebel, and G.C. Gallopin. 2016. Crafting usable knowledge for sustainable development. Proceedings of the National Academy of Sciences of the United States of America 113:4,570-4,578, https://doi.org/10.1073/ pnas.1601266113.

Copping, A. 2018. The State of Knowledge for Environmental Effects: Driving Consenting/ Permitting for the Marine Renewable Energy Industry. Ocean Energy Systems, $25 \mathrm{pp}$.

Cullen-Unsworth, L.C., L.Mtwana Nordlund, J. Paddock, S. Baker, L.J. McKenzie, and R.K.F. Unsworth. 2013. Seagrass meadows globally as a coupled social-ecological system: Implications for human wellbeing. Marine Pollution Bulletin 83:387-397, https://doi.org/10.1016/ j.marpolbul.2013.06.001.

Cutts, B.B., D.D. White, and A.P. Kinzig. 2011 Participatory geographic information systems for the co-production of science and policy in an emerging boundary organization. Environmental Science \& Policy 14:977-985, https://doi.org/ 10.1016/j.envsci.2011.05.012.

Cvitanovic, C., A.J. Hobday, L. van Kerkhoff, S.K. Wilson, K. Dobbs, and N.A. Marshall. 2015 Improving knowledge exchange among scientists and decision-makers to facilitate the adaptive governance of marine resources: A review of knowledge and research needs. Ocean \& Coastal Management 112:25-35, https://doi.org/10.1016/ j.ocecoaman.2015.05.002.
Dadswell, M.J., R.A. Rulifson, and G.R. Daborn. 1986. Potential impact of large-scale tidal power developments in the upper Bay of Fundy on fisheries resources of the Northwest Atlantic. Fisheries 11:26-35, https://doi.org/10.1577/15488446(1986)011<0026:PIOLTP>2.0.CO;2.

Davis, S.N., D. Mahatmya, P.W. Garner, and R.M. Jones. 2015. Mentoring undergraduate scholars: A pathway to interdisciplinary research? Mentoring \& Tutoring: Partnership in Learning 23:427-440, https://doi.org/10.1080/ 13611267.2015.1126166.

Defne, Z., K.A. Haas, and H.M. Fritz. 2011. Numerical modeling of tidal currents and the effects of power extraction on estuarine hydrodynamics along the Georgia coast, USA. Renewable Energy 36:3,461-3,471, https://doi.org/10.1016/ j.renene.2011.05.027.

Doerschuk, P., C. Bahrim, J. Daniel, J. Kruger, J. Mann, and C. Martin. 2016. Closing the gaps and filling the STEM pipeline: A multidisciplinary approach. Journal of Science Education and Technology 25:682-695, https://doi.org/10.1007/ s10956-016-9622-8.

Fallon, D., M. Hartnett, A. Olbert, and S. Nash. 2014 The effects of array configuration on the hydroenvironmental impacts of tidal turbines. Renewable Energy 64:10-25, https://doi.org/10.1016/j.renene. 2013.10.035.

Fox, C.J., S. Benjamins, E.A. Masden, and R. Miller 2017. Challenges and opportunities in monitoring the impacts of tidal-stream energy devices on marine vertebrates. Renewable and Sustainable Energy Reviews 81:1,926-1,938, https://doi.org/ 10.1016/j.rser.2017.06.004.

Hall-Arber, M., C. Dyer, J. Poggie, J. McNally, and R. Gagne. 2001. New England's Fishing Communities. MITSG 01-15, Massachusetts Institute of Technology Sea Grant, Cambridge, MA, 426 pp.

Hart, D.D., J.L. Buizer, J.A. Foley, L.E. Gilbert, L.J. Graumlich, A.R. Kapuscinski, J.G. Karmer, M.A. Palmer, D.R. Peart, and L. Silka. 2016.

Mobilizing the power of higher education to tackle the grand challenge of sustainability: Lessons from novel initiatives. Elementa: Science of the Anthropocene 4:000090, https://doi.org/10.12952/ journal.elementa.000090.

International Passamaquoddy Fisheries Board. 1960. Passamaquoddy Fisheries Investigations 19571958: Report to the International Joint Commission. Special Scientific Report - Fisheries No. 360, US Fish and Wildlife Service, $40 \mathrm{pp}$.

Jansujwicz, J.S., and T.R. Johnson. 2015. The Maine Tidal Power Initiative: Transdisciplinary sustainability science research for the responsible development of tidal power. Sustainability Science 10:75-86, https://doi.org/10.1007/ s11625-014-0263-7.

Johnson, T.R., A. Henry, and C. Thompson. 2014. In Their Own Words: Fishermen's Perspective of Community Resilience. Maine Sea Grant, Orono, ME, $21 \mathrm{pp}$

Juhl, L., K. Yearsley, and A.J. Silva. 1997 Interdisciplinary project-based learning through an environmental water quality study. Journal of Chemical Education 74:1,431-1,433, https://doi.org/ 10.1021/ed074p1431.

Kilcher, L., R. Thresher, and H. Tinnesand. 2016. Marine hydrokinetic energy site identification and ranking methodology: Part II. Tidal energy. NREL/ TP-5000-66079, National Renewable Energy Laboratory, Golden, CO, 30 pp., https://doi.org/ 10.2172/1330619.

Koch, F.D., A. Dirsch-Weigand, M. Awolin, R.J. Pinkelman, and M.J. Hampe. 2017. Motivating first-year university students by interdisciplinary study projects. European Journal of Engineering Education 42:17-31, https://doi.org/10.1080/ 03043797.2016.1193126. 
Lang, D.J., A. Weik, M. Bergmann, M. Stauffacher, P. Martens, P. Moll, M. Swilling, and C.J. Thomas 2012. Transdisciplinary research in sustainability science: Practice, principals and challenges. Sustainability Science 7:25-43, https://doi.org/ 10.1007/s11625-011-0149-x.

Lavery, A.C., P.H. Wiebe, T.K. Stanton, G.L. Lawson, M.C. Benfield, and N. Copley. 2007. Determining dominant scatterers of sound in mixed zooplankton populations. Journal of Acoustic Society of America 122:3,304-3,326, https://doi.org/ 10.1121/1.2793613.

Leeney, R.H., D. Greaves, D. Conley, and A.M. O’Hagan. 2014. Environmental Impact Assessments for wave energy developments - Learning from existing activities and informing future research priorities. Ocean \& Coastal Management 99:14-22, https://doi.org/10.1016/ j.ocecoaman.2014.05.025.

Lester, S.E., K.L. McLeod, H. Tallis, M. Ruckelshaus, B.S. Halpern, P.S. Levin, F.P. Chavez, C. Pomeroy, B.J. McCay, C. Costello, and others. 2010. Science in support of ecosystem-based management for the US West Coast and beyond. Biological Conservation 143:576-587, https://doi.org/10.1016/ j.biocon.2009.11.021.

Levin, P.S., M.J. Fogarty, S.A. Murawski, and D. Fluharty. 2009. Integrated ecosystem assessments: Developing the scientific basis for ecosystem-based management of the ocean. PLoS Biology 7(1):e1000014, https://doi.org/10.1371/ journal.pbio.1000014.

Luna-Reyes, L.F., L.J. Black, W. Ran, D.L. Andersen, H. Jarman, G.P. Richardson, and D.F. Andersen. 2018. Modeling and simulation as boundary objects to facilitate interdisciplinary research. Systems Research and Behavioral Science 36:494-513, https://doi.org/10.1002/sres.2564.

Mackinson, S., and L. Nottestad. 1998. Combining local and scientific knowledge. Reviews in Fish Biology and Fisheries 8:481-490, https://doi.org/ 10.1023/A:1008847106984.

MacLeod, M. 2018. What makes interdisciplinarity difficult? Some consequences of domain specificity in interdisciplinary practice. Synthese 195:697-720, https://doi.org/10.1007/s11229-016-1236-4.

Maurer, D., H. Nguyen, G. Robertson, and T. Gerlinger. 1999. The infaunal trophic index (ITI): Its suitability for marine environmental monitoring. Ecological Applications 9:699-713, https://doi.org/ 10.1890/1051-0761(1999)009[0699:TITIII]2.0.CO;2.

McDowell, G., and J.D. Ford. 2014. The socio-ecological dimensions of hydrocarbon development in the Disko Bay region of Greenland: Opportunities, risks, and tradeoffs. Applied Geography 46:98-110, https://doi.org/10.1016/j.apgeog.2013.11.006.

Melvin, G.D., and N.A. Cochrane. 2015. Multibeam acoustic detection of fish and water column targets at high-flow sites. Estuaries and Coasts 38:S227-S240, https://doi.org/10.1007/ 12237-014-9828-Z.

Pischke, E.C., J.L. Knowlton, C.C. Phifer, J.G. Lopez, T.S. Propato, A. Eastmond, T.M. de Souza, M. Kuhlberg, V.P. Risso, S.R. Veron, and others. 2017. Barriers and solutions to conducting large international, interdisciplinary research projects. Environmental Management 60:1,011-1,021, https://doi.org/10.1007/s00267-017-0939-8.

Rao, S., H. Xue, M. Bao, and S. Funke. 2016. Determining tidal turbine farm efficiency in the Western Passage using the disc actuator theory. Ocean Dynamics 66:41-57, https://doi.org/10.1007/ s10236-015-0906-y.

Rehme, S.E., L.A. Powell, and C.R. Allen. 2011. Multimodel inference and adaptive management. Journal of Environmental Management 92:1,360-1,364, https://doi.org/ 10.1016/j.jenvman.2010.10.012.
Ross, T., and R. Lueck. 2005. Estimating turbulent dissipation rates from acoustic backscatter. Deep Sea Research Part / 52:2,353-2,365, https://doi.org/ 10.1016/j.dsr.2005.07.002

Roy, E.D., A.T. Morzillo, F. Seijo, S.M.W. Reddy, J.M. Rhemtulla, J.C. Milder, T. Kuemmerle, and S.L. Martin. 2013. The elusive pursuit of interdisciplinarity at the human-environment interface. Bioscience 63:745-753, https://doi.org/10.1525/ bio.2013.63.9.10.

Roy, S.G., S.P. de Souza, B. McGreavy, C.G. Druschke, D.D. Hart, and K. Gardner. 2019. Evaluating core competencies and learning outcomes for training the next generation of sustainability researchers. Sustainability Science 15:618-631, https://doi.org/ 10.1007/s11625-019-00707-7.

Shen, H., G.B. Zydlewski, H.A. Viehman, and G. Staines. 2016. Estimating the probability of fish encountering a marine hydrokinetic device. Renewable Energy 97:746-756, https://doi.org/ 10.1016/j.renene.2016.06.026.

Smith, J.D., and D.E. Gaskin. 1974. The diet of harbor porpoises (Phocoena phocoena (L.)) in coastal waters of Eastern Canada, with special reference to the Bay of Fundy. Canadian Journal of Zoology 52:777-782, https://doi.org/10.1139/ z74-102.

Staines, G., G.B. Zydlewski, and H.A. Viehman. 2019. Changes in relative fish density around a deployed tidal turbine during on-water activities. Sustainability 11:6262, https://doi.org/10.3390/ su11226262.

Teixeira, J.B., A.S. Martins, H.T. Pinheiro, N.A. Secchin, R. Leão de Moura, and A.C. Bastos. 2013. Traditional Ecological Knowledge and the mapping of benthic marine habitats. Journal of Environmental Management 115:241-250, https://doi.org/10.1016/j.jenvman.2012.11.020.

Thiébot, J., P.B. du Bois, and S. Guillou. 2015. Numerical modeling of the effect of tidal stream turbines on the hydrodynamics and the sediment transport - Application to the Alderney Race (Raz Blanchard), France. Renewable Energy 75:356-365, https://doi.org/10.1016/ j.renene.2014.10.021.

Thomas, J.D. 1993. Biological monitoring and tropical biodiversity in marine environments: A critique with recommendations, and comments on the use of amphipods as bioindicators. Journal of Natural History 27:795-806, https://doi.org/ 10.1080/00222939300770481.

Viehman, H.A., and G.B. Zydlewski. 2015. Fish interactions with a commercial-scale tidal energy device in the natural environment. Estuaries and Coasts 38:241-252, https://doi.org/10.1007/ s12237-014-9767-8.

Viehman, H.A., and G.B. Zydlewski. 2017. Multiscale temporal patterns in fish presence in a highvelocity tidal channel. PLoS One 12(5):e0176405, https://doi.org/10.1371/journal.pone.0176405.

Viehman, H.A., T. Boucher, and A.M. Redden. 2018. Winter and summer differences in probability of fish encounter (spatial overlap) with MHK devices. International Marine Energy Journal 1:9-18, https://doi.org/10.36688/imej.1.9-18.

Warren, J.D., and P.H. Wiebe. 2008. Accounting for biological and physical sources of acoustic backscatter improves estimates of zooplankton biomass. Canadian Journal of Fisheries and Aquatic Sciences 65:1,321-1,333, https://doi.org/10.1139/ F08-047.

\section{ACKNOWLEDGMENTS}

We offer our sincere appreciation to Chris Bartlett, Chris Johnson, Bob Lewis, Butch Harris, Pat Donahue, the Bishop family, and others of the Eastport community who assisted, guided, advised, and participated in our study. The WPSRC was supported by a grant from the University of Maine System Research Reinvestment Fund. Graduate student support and funding for community meetings was provided by the Senator George J. Mitchell Center for Sustainability Solutions. Equipment for the hydroacoustic and passive acoustic monitoring research as well as some personnel time was supported by the US Department of Energy's Office of Energy Efficiency and Renewable Energy (EERE) under Water Power Program Award Number DE-EE0007820 as a subaward to the University of Maine by the Ocean Renewable Power Company. BigEye binoculars and passive acoustic recorders were provided on loan for this research from Mark Baumgartner and Turbulent Research Inc., respectively. This project was also supported by the USDA National Institute of Food and Agriculture, Hatch (or McIntire-Stennis, Animal Health, etc.) Project Number ME0-031716 through the Maine Agricultural \& Forest Experiment Station. Maine Agricultural and Forest Experiment Station Publication Number 3798. The authors thank the editor and two anonymous reviewers for their thoughtful feedback on an earlier version of this manuscript.

\section{AUTHORS}

Kristina Cammen (kristina.cammen@maine.edu) is Assistant Professor, Gabriella Marafino is a master's student, and Sarah Burton is an undergraduate, all at the School of Marine Sciences, University of Maine, Orono, ME, USA. Jillian Dow is an undergraduate in the Division of Environmental and Biological Sciences, University of Maine at Machias, Machias, ME, USA. Emma Dullaert and Madalyn Jorge are undergraduates at the School of Marine Sciences, and Kate Macolini is an undergraduate in the Department of Civil and Environmental Engineering, all three at University of Maine, Orono, ME, USA. Louise McGarry and Christopher Tremblay are Research Associates at the School of Marine Sciences, University of Maine, Orono, ME, USA. Jessica Jansujwicz is Research Assistant Professor, Department of Wildlife, Fisheries, and Conservation Biology, and Senator George J. Mitchell Center for Sustainability Solutions, University of Maine, Orono, ME, USA. Tora Johnson is Associate Professor, Division of Environmental and Biological Sciences, University of Maine at Machias, Machias, ME, USA. Lauren Ross is Assistant Professor, Department of Civil and Environmental Engineering, and Gayle Zydlewski is Professor, School of Marine Sciences, both at University of Maine, Orono, ME, USA.

\section{ARTICLE CITATION}

Cammen, K., G. Marafino, S. Burton, J. Dow, E. Dullaert, M. Jorge, K. Macolini, L. McGarry, C. Tremblay, J. Jansujwicz, T. Johnson, L. Ross, and G. Zydlewski. 2021. Interdisciplinary research collaborative trains students to see through turbulent systems. Oceanography 34(1):256-267, https://doi.org/10.5670/oceanog.2021.102.

\section{COPYRIGHT \& USAGE}

This is an open access article made available under the terms of the Creative Commons Attribution 4.0 International License (https://creativecommons.org/ licenses/by/4.0/), which permits use, sharing, adaptation, distribution, and reproduction in any medium or format as long as users cite the materials appropriately, provide a link to the Creative Commons license, and indicate the changes that were made to the original content. 